\title{
O CONATUS IMAGINATIVO EM ESPINOSA: A PRODUÇÃO DA CONTINGÊNCIA E DA IDEIA DE FINALIDADE
}

\author{
Juarez Lopes Rodrigues ${ }^{1}$
}

\begin{abstract}
Resumo: O escopo deste artigo é explicitar a lógica da produção das paixōes, através do conatus imaginativo em Espinosa. Essa lógica envolve a compreensão dos afetos primitivos de alegria, tristeza e desejo que irấo compor as paixôes pelas quais somos determinados a pensar e agir, e, ao mesmo tempo, produzem a ilusão da liberdade de escolha indeterminada. Será possível observar como essa lógica do conatus imaginativo, ao sofrer a flutuação do ânimo, produzirá as modalidades de contingente e possível, que são responsáveis pela ilusão da escolha indeterminada, isto é, da vontade livre. Tentar-se-á demonstrar que a experiência da liberdade como poder dos contrários pela qual os homens acreditam determinar os fins pelos quais o apetite/desejo se modifica em paixóes reduz-se à experiência da flutuação do ânimo. Essa ilusão da liberdade indeterminada surge, porque os homens desconhecem a sua essência (conatus) de maneira adequada, fato que os leva a identificar as causas eficientes da produção dos afetos como causas finais.
\end{abstract}

Palavras-chave: Liberdade. Paixôes. Afetos. Possível. Contingente. Espinosa.

\section{INTRODUÇÃo}

Após a exclusão da ideia de faculdades da mente, realizada pela Parte II da Ética, ${ }^{2}$ Espinosa irá realizar, na Parte III, uma análise do $c o n a t u s,{ }^{3}$ isto é,

\footnotetext{
${ }_{1}^{1}$ Doutor em Filosofia pela Universidade de São Paulo (USP), São Paulo, SP - Brasil. (DD https:// orcid.org/0000-0002-5281-0916 E-mail: juarez_rodrigues@hotmail.com

${ }^{2}$ A recusa de Espinosa em admitir a existência de faculdades incondicionadas decorre da identificação que ele realiza entre a ideia e a volição, nas Proposiçóes 48 e 49 da Parte II da Ética. Sobre isso, veja-se RODRIGUES (2014, p. 89-116).

${ }^{3}$ Neste artigo, nós nos limitaremos a realizar uma análise da dimensão imaginativa do conatus enquanto produz ideias inadequadas, isto é, enquanto é externamente determinado pela ordem comum da natureza. No entanto, há também a dimensão racional enquanto a mente produz ideias adequadas, isto é, enquanto a mente é internamente disposta a compreender a ordem necessária da natureza. Assim, não entendemos por conatus imaginativo uma dimensão facultativa dessa potência, mas a constância em que o indivíduo é maximamente imaginativo. É importante lembrarmos que, para Espinosa, os três gêneros de conhecimentos são sempre simultâneos.
}

https://doi.org/10.1590/0101-3173.2021.v44n1.14.p205

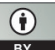

This is an open-access article distributed under the terms of the Creative Commons Attribution License. 
da nossa essência singular enquanto interage com as causas externas, através do encontro fortuito com as coisas exteriores. É através dessa interação que compreendemos o surgimento dos afetos humanos e a maneira pela qual o conatus imaginativo produz a ilusão da liberdade de escolha. Por conseguinte, veremos que todas as nossas operaçóes, no âmbito imaginativo, são determinadas pela maneira como somos afetados através de nossa interação com a ordem comum da natureza, ${ }^{4}$ a qual produz as ideias de contingência e possível. Espinosa propóe uma ciência dos afetos pela qual considera que as açóes e apetites humanos seguem de seu conatus, tal como a ciência matemática pode deduzir de maneira certa todas as linhas, planos e corpos. É através da compreensão dos nossos apetites, afetos e desejos que compreenderemos o nosso estado de passividade em relação às causas exteriores e a produçáo da ideia de finalidade e de livre escolha, ilusão oriunda da ideia de livre arbítrio.

\section{As DETERMinaÇóES PASSIONAIS Do CONATUS}

Ao construir geneticamente, a partir das noçóes comuns da razão, a sua teoria das paixóes, Espinosa nos mostra como no homem o conatus é consciência de si e, enquanto tal, ele é desejo. ${ }^{5}$ Ora, no apêndice da Parte I,

\footnotetext{
${ }^{4}$ A noção de ordem é fundamental para compreendermos a Ética de Espinosa, pois, em sua filosofia, todas as coisas são produzidas por Deus e seguem necessariamente da natureza divina. Espinosa distinguirá essa ordem concebida pelo intelecto, isto é, a ordem necessária da natureza, daquela ordem concebida pela imaginaçáo, isto é, a ordem comum da natureza (comuni naturae ordine), na qual habitam o contingente e o possível. Desse modo, tudo o que existe é necessário e determinado, porém, esse conhecimento não garante que possamos conhecer o nexo infinito de causas. Por esse motivo, o contingente e o possível somente podem ser pensados imaginativamente, pois não possuem lugar numa filosofia determinista. Por conseguinte, a privaçâo de conhecimento da causalidade real dos acontecimentos nos insere na ordem imaginativa, isto é, na ordem comum da natureza.

${ }^{5}$ Espinosa afirma, na P9 da Parte III, que a mente, seja na adequação, seja na inadequação, se esforça para perseverar em seu ser, por uma duração indefinida, e é cônscia deste seu esforço (conatus). Logo, toda análise para compreendermos as açóes e os afetos humanos deve ser pensada a partir da simultaneidade das causas e dos efeitos que constituem a essência e a existência dos homens, conforme afirma o escólio da Proposição: "Este esforço, quando referido à só Mente, chama-se Vontade; mas quando é referido simultaneamente à Mente e ao Corpo chama-se Apetite que, portanto, não é nada outro que a própria essência do homem, de cuja natureza necessariamente segue aquilo que serve à sua conservação; e por isso o homem é determinado a fazê-lo." Desse modo, não há nenhuma diferença entre o apetite e o desejo, senão pelo fato de que o desejo é geralmente referido aos homens enquanto são cônscios de seu apetite: “[...] o Desejo é o apetite quando dele se tem consciência." É por isso que o desejo receberá uma reformulação na Definiçẫo geral dos afetos que encerra a Parte III: "O Desejo é a própria essência do homem enquanto é concebida determinada a fazer (agir) algo por uma dada afecção sua qualquer." Porém, um detalhe importante é que Espinosa não definiu o desejo dessa forma, anteriormente, porque o homem pode não ter a consciência de seu apetite (ideia da ideia das afecçóes do corpo) e, no entanto, o apetite permanecerá o mesmo (ideia das afecçōes e afecçōes do corpo).
} 
Espinosa já afirma ser admitido por todos que os homens nascem ignorantes das causas das coisas, e que todos têm o apetite de buscar o que lhes é útil, sendo disso conscientes. A ilusão da liberdade é denunciada por Espinosa como uma decorrência, embora imaginária, do próprio funcionamento do conatus, pois a consciência das voliçóes e dos seus apetites (desejos) surge através do signo da utilidade e seus objetivos são perseguidos através da ideia de finalidade. No entanto, os homens desconhecem as causas pelas quais eles são dispostos a apetecer e a querer, pois desconhecem a lógica que envolve a produção das paixôes humanas:

Ora, a causa que é dita final nada mais é que o próprio apetite humano, enquanto considerado como princípio ou causa primeira de uma coisa. Por exemplo, quando dizemos que a habitação foi a causa final desta ou daquela casa, certamente não inteligimos nada outro senão que um homem, por ter imaginado as comodidades da vida doméstica, teve o apetite de edificar uma casa. Por isso, a habitaçấo, enquanto considerada como causa final, nada outro é que este apetite singular, que na realidade é causa eficiente, considerada como primeira porque os homens comumente ignoram as causas de seus apetites. (ESPINOSA, 2015, EIV Prefácio, p. 375).

Nesse exemplo da habitação do Prefácio da Parte IV, Espinosa aborda o processo de ilusão da escolha. Ao tomarmos consciência de nossos apetites, isto é, quando conhecemos os nossos desejos, podemos compreender como nos determinamos a realizar as escolhas pelas quais somos determinados. Tomar consciência dos nossos desejos, num primeiro momento, é conhecer os nossos apetites, isto é, a causa pela qual fazemos algo e experimentamos as açóes e paixôes, tal como Espinosa (2015, p. 381) enfatiza, na definição 7 da Parte IV: "Por fim, por causa do qual fazermos algo, entendo o apetite." Todavia, conforme Espinosa demonstra, no exemplo da habitação, ao conhecermos adequadamente o apetite, não o entendemos mais como causa primeira de nossas açóes e paixóes, mas como um efeito determinado, o qual é a causa eficiente dos pensamentos, açóes e paixões.

Ora, apesar de o apetite não ser a causa primeira, ele é o motivo pelo qual somos determinados a perseguir uma finalidade. É através do amor que podemos identificar o motivo pelo qual fazemos algo, segundo aponta

Ora, se Espinosa explicasse o desejo pelo apetite, entâo o desejo dependeria do apetite e ocorreria uma tautologia $(\mathrm{A}=\mathrm{A})$, já que apetite e desejo são o mesmo. Para compreender todos os esforços do homem, tais como apetite (esforço da mente e do corpo), vontade (esforço da mente somente), desejo (consciência do esforço da mente e do corpo (apetite)) e ímpeto (esforço do corpo somente), o filósofo define o desejo, de modo que a causa dele esteja englobada em sua essência. 
Matheron (1988, p. 93): “[...] o amor confere imediatamente uma estrutura finalista à nossa conduta e a nossas obras." Assim, tudo aquilo que uma vez nos deleitou tenderemos a percebê-lo o mais vivamente possível, isto é, a fazer a coisa existir atualmente. É através da imaginação que reproduzimos o passado, quando ele está ausente, ou imaginamos o futuro no qual o passado será reproduzido novamente, caso estejamos privados no presente das coisas que amamos. Tal é o caso do exemplo da habitação, porque as comodidades que deleitaram o indivíduo excitaram o seu apetite a reproduzir os meios que possibilitam a construção da habitação.

Contudo, não temos consciência dos estímulos que determinaram o deleite das comodidades, mas apenas consciência do apetite (desejo) que nos aparece como finalidade da ação. De fato, a ideia de habitação surge como um desejo a cujas causas não conseguimos remontar, pois ignoramos as condições. Conforme observa Matheron, a consciência do apetite (desejo) acarreta a impressão de ter descoberto uma causa primeira, o que possui dois desdobramentos:

Há, por um lado, o agente que surge para ele mesmo como incondicionado, ele se estima livre. Há, por outro lado (pois é necessário, apesar de tudo, assinalar um motivo para nossa escolha) a causa final, ou seja, o objeto mesmo desejado que, como se ele preexistisse de maneira misteriosa a sua própria realização, parece inclinar a vontade livre do agente por uma espécie de atração que ele exerceria sobre ela. (MATHERON, 1988, p. 104).

Matheron observa que essa crença não implica nenhuma teoria filosófica particular sobre a natureza do livre-arbítrio, seja aquela da indeterminação da vontade, seja sobre a determinação do bem. O que Espinosa descreve é a infraestrutura comum a todas as doutrinas: "[...] todas, ou quase todas, repousam sobre a hipótese de um sujeito ao mesmo tempo livre e sensibilizado ao apelo dos valores." (MATHERON, 1988, p. 105). O erro consiste em crer que exista uma qualidade intrínseca nas coisas, a qual lhes pertenceria essencialmente e deveria ser reconhecida como tal por todos os homens, e não em suas relaçôes momentâneas ao nosso organismo individual. As coisas são vistas, dessa maneira, como atraentes, e nós as amamos, porque elas são representadas como bens em si mesmos.

O desejo, essência mesma do homem enquanto é determinado a fazer alguma coisa, torna-se paixão toda vez que o que segue dessa essência não segue 
unicamente dela; ele se deixa orientar pelo exterior, por meio das deformaçóes que sofremos através das impressóes sensíveis. Assim, desde que um organismo se torna capaz de suportar as variações passivas pelas quais o desejo se especifica, percebendo quer um aumento, quer uma diminuição de sua potência, a mente percebe a diferença entre esses dois estados e a passagem de um para outro. ${ }^{6}$ Além desses dois estados de consciência, há um estado neutro no qual as alterações percebidas pelo indivíduo são puramente representativas, sem qualquer nuance afetiva particular, conforme o primeiro postulado da Parte III da Ética: "O corpo humano pode ser afetado de muitas maneiras pelas quais sua potência de agir é aumentada ou diminuída, e também de outras que não tornam sua potência de agir nem maior nem menor." (ESPINOSA, 2015, p. 237). Os afetos primitivos dos quais todos os outros seráo derivados são percebidos, quando há uma variação que diminui ou aumenta a potência de agir do corpo, isto é, as afecçóes percebidas ou contrariam ou favorecem a sua capacidade de agir mais rápida ou mais lentamente, de perceber mais ou menos obstáculos ou exercer as suas funçôes da melhor maneira. Visto que a mente e o corpo são um só e o mesmo indivíduo, “[...] o que quer que aumente ou diminua a potência de agir de nosso Corpo, a ideia desta mesma coisa aumenta ou diminui, favorece ou coíbe a potência de pensar de nossa Mente." (ESPINOSA, 2015, EIII P11, p. 255).

Conforme acrescenta Matheron, paralelamente, as ideias dessas variaçóes "negativas" diminuem e contrariam a potência de pensar da mente: “[...] elas a distanciam do estado que seria o seu se, da ideia clara e distinta da essência de seu corpo, ela pudesse pela ajuda de seus próprios recursos deduzir (e produzir) suas próprias modificaçôes." (1988, p. 96). As paixões "negativas" da mente fazem obstáculo ao esforço da mente humana de compreensão de sua própria origem e natureza; tal é, para Espinosa, o sentido pleno da tristeza (tristitia). Por outro lado, as variaçóes "positivas" ocorrem, quando aumentam e favorecem a potência de agir do corpo, na medida em que são atenuadas as deformaçóes anteriores, assim proporcionando ao corpo o seu melhor funcionamento possível. Por isso, na alegria (laetitia), os estados mentais favorecem também a mente a pensar, tornando-a mais apta a deduzir as suas próprias ideias e, no limite, compreender as suas próprias açóes: "Assim, por

\footnotetext{
${ }^{6} \mathrm{Na}$ definição geral dos afetos, Espinosa especifica que não se trata de uma objetivação de valores: "Porém, é de notar que, quando digo uma força de existir maior ou menor do que antes, náo entendo que a Mente compara a constituiçáo presente do Corpo com a passada, mas que a ideia que constitui a forma do afeto afirma algo sobre o corpo que na verdade envolve mais ou menos realidade do que antes." (ESPINOSA, 2015, p. 367).
} 
Alegria, entenderei na sequência a paixão pela qual a Mente passa a uma maior perfeição. Por tristeza, a paixão pela qual ela passa a uma menor perfeição.” (ESPINOSA, 2015, EIII P11 esc., p. 257).

Assim entendidas, alegria e tristeza são paixôes que representam um progresso de consciência sobre os estados diferenciados do próprio corpo. Observamos justamente que, nos corpos mais complexos, são orientaçóes que conduzem os conatus dos indivíduos a uma sobrevivência mais consciente sobre o seu instinto de conservação. $\mathrm{O}$ conatus, em seu esforço de atualização e perseverança na existência, conduzirá o indivíduo a prolongar toda excitaçáo alegre e a evitar toda excitação triste, ou seja, ele buscará o prazer e fugirá da dor.

Entretanto, o amor (amor) e o ódio (odium) correspondem a uma nova etapa, pois pressupóem uma nova diferenciaçáo corporal e um novo progresso da consciência. $\mathrm{O}$ amor e o ódio são os próprios afetos de alegria e tristeza conjuntamente à ideia de causa exterior (ESPINOSA, 2015, EIII def. 1 e 2, p. 343-345). O ódio pressupóe a memória, e o amor, além desta, pressupóe implicitamente a possibilidade de imaginar uma coisa que não está realmente presente, o que constatamos somente em organismos mais complexos. Pelo fato de tendermos a prolongar tanto quanto possível uma excitação alegre que nos afeta ou afetou, facilmente compreendemos a ligação entre o amor e a conservação das imagens: "A Mente, o quanto pode, esforça-se para imaginar coisas que aumentam ou favorecem a potência de agir do Corpo." (ESPINOSA, 2015, EIII P12, p. 259).

Todavia, é sempre bom ressaltar que a excitação gerada pelas coisas que imaginamos indica mais os afetos do nosso corpo do que a natureza dos corpos externos. Essa ligação entre as imagens é ainda mais excitada, quando somos afetados por imagens que nos entristecem, pois resistimos a essas variaçóes desfavoráveis que diminuem a potência do conatus. Assim, tentamos retornar ao estado anterior à aparição das imagens, excluindo as coisas presentes ou ausentes que causam a tristeza: "Quando a Mente imagina coisas que diminuem ou coíbem a potência de agir do Corpo, esforça-se, o quanto pode, para recordar coisas que excluem a existência daquelas." (ESPINOSA, 2015, EIII P13, p. 259). O conatus sempre resistirá à tristeza, tentando viver ou reviver o maior número possível de imagens alegres, seja de coisas presentes, seja de ausentes. ${ }^{7} \mathrm{O}$ tempo surge como elemento fundamental para os indivíduos que

7 Conf. P36 da Parte III: "Quem recorda de uma coisa com que se deleitou uma vez deseja possuí-la com as mesmas circunstâncias em que pela primeira vez deleitou-se com ela" e Escólio: "Esta Tristeza, enquanto concerne à ausência do que amamos, chama-se Saudade (desiderium).” (ESPINOSA, 2015, p. 295). 
podem experimentar os afetos de amor e ódio, porque ele pode ampliar o seu campo perceptivo para além das sensaçóes imediatas e nos representar as coisas ausentes, mas que poderão estar disponíveis no futuro.

Quando imaginamos, submetidos apenas à ordem comum da natureza, não conseguimos explicar a origem real da fascinação que os objetos amados exercem sobre nós. Temos consciência de desejá-los, porque os amamos e porque eles são causa de alegria. Mas não sabemos o porquê, já que não conhecemos a verdadeira natureza do conatus, nem das coisas exteriores que nos afetam. Acreditamos que somos livres para amar os objetos com os quais entramos em relação e também que eles possuem valores objetivos, isto é, que eles merecem e possuem valores intrínsecos que os tornam dignos de serem conquistados, de modo que os representamos como um bem em si mesmo.

A mesma lógica é válida para os objetos que nos afetam de tristeza e consequentemente serão odiados e evitados ou aniquilados, porque seráo considerados como um mal em si mesmos. No entanto, tanto os afetos de amor quanto os de ódio dependem da memória corporal e da maneira como eles foram concatenados, porque, "[...] se o Corpo humano tiver sido afetado uma vez por dois ou mais corpos em simultâneo, quando depois a Mente imaginar um deles, imediatamente se recordará dos outros." (ESPINOSA, 2015, EII P18, p. 169). Espinosa demonstra que, submetidos à ordem comum da natureza, não escolhemos o modo como seremos afetados, mas somos afetados conforme as imagens e os traços corporais foram impressos em nosso corpo. E, apesar de relacionarmos a alegria ou tristeza aos objetos externos, cumpre enfatizar que as variações afetivas dependem mais daquilo que está "em nós", isto é, da constituição do corpo próprio, do que da natureza dos corpos externos.

Porém, as associaçôes entre a memória corporal e os objetos externos que nos afetam na ordem comum ganham uma dimensão sem limites definidos, já que "[...] qualquer coisa pode ser, por acidente, causa de Alegria, Tristeza ou Desejo.” (ESPINOSA, 2015, EIII P15, p. 261). As variações afetivas são concatenadas na memória simultaneamente com as afeçóes e ideias das coisas externas que não aumentam e nem diminuem a potência do conatus. Visto que as concatenaçóes foram ordenadas conforme o corpo foi afetado pelo encontro com os corpos externos na ordem comum, quando a mente se depara com um afeto neutro, ele pode estar encadeado com outro alegre ou triste na memória. Por esse motivo, a mente pode negligenciar a verdadeira causa de sua paixão: "Só por termos contemplado uma coisa com um afeto de 
Alegria ou Tristeza de que ela própria não é a causa eficiente, podemos amá-la ou odiá-la." (ESPINOSA, 2015, EIII P15 cor., p. 263).

Logo, mesmo sem razão para a variação afetiva, a mente ignorante da verdadeira causa eficiente do afeto atribui àquela coisa a variação afetiva, concatenando a afecção como causa eficiente. Ao atribuir a uma coisa um afeto de amor ou ódio de que ela própria náo é a causa eficiente, a mente atribui à coisa a causa do seu estado afetivo, gerando a ideia de simpatia (Sympathiâ) ou antipatia (Antiphathiâ). Espinosa acrescenta que esses afetos também podem ser atribuídos às coisas que produzem variaçóes afetivas apenas por terem algo semelhante aos objetos que costumam afetar-nos com aqueles afetos. Nesse momento, essa lógica de transferência afetiva depende apenas da mente e da ordem comum da natureza, isto é, dos acasos dos encontros conjuntamente com a memória corporal.

Entretanto, a transferência afetiva que é atribuída, quando a própria coisa não é causa eficiente, mas por acidente, também poderá ocorrer quando a própria coisa é causa eficiente de afetos contrários: "Se imaginarmos uma coisa, que costuma nos afetar com um afeto de Tristeza, ter algo semelhante a outra, que costuma nos afetar com um igualmente intenso afeto de Alegria, nós a odiaremos e a amaremos simultaneamente." (ESPINOSA, 2015, EIII P15, p. 265). Essa constituição da mente, derivada de dois afetos contrários, Espinosa denomina flutuação do ânimo (fluctuatio animi). O filósofo a identifica com a dúvida cognitiva (dubitatio), isto é, com o surgimento de imagens e afecçóes contrárias, pelas quais o indivíduo hesita a respeito de qual ação ou ideia deve ser tomada, sendo que tal variação afetiva pode ser mínima (ceticismo) ou máxima (indecisão). Não há uma diferença de natureza entre a fluctuatio e a dubitatio, mas apenas de grau, isto é, segundo o mais ou o menos. Em ambos os casos, tal como no exemplo do menino no escólio da P44 da Parte $\mathrm{II}^{8}$, a flutuação da imaginação não contempla nenhuma afecção em ordem,

\footnotetext{
8 "Suponhamos, pois, um menino que pela primeira vez ontem pela manhă tenha visto Pedro, ao meiodia Paulo e ao entardecer Simeão, e que hoje de novo pela manhã tenha visto Pedro. Pela Proposiçấo 18 desta parte é patente que tão logo veja a luz matutina, imaginará o sol percorrendo a mesma parte do céu que no dia anterior, ou seja, um dia inteiro, e simultaneamente com o amanhecer imaginará Pedro, com o meio-dia Paulo e com o entardecer Simeão, isto é, imaginará a existência de Paulo e de Simeão com relação ao tempo futuro; e pelo contrário, se ao entardecer vir Simeão, relacionará Paulo e Pedro ao tempo passado, a saber, imaginando-os simultaneamente com o tempo passado; e isto com tanto mais constância quanto com mais frequência os tenha visto nessa ordem. Porque, se acontece alguma vez de num outro entardecer ver Jacó em lugar de Simeão, então no dia seguinte imaginará com o entardecer ora Simeão, ora Jacó, mas não a ambos em simultâneo; pois supóe-se que viu no período da tarde só um deles, não ambos em simultâneo. E assim a sua imaginação flutuará e com o futuro entardecer imaginará ora um, ora outro, isto é, não contemplará nenhum certamente, mas ambos
} 
porém, todas surgem como possíveis, produzindo a ideia de contingência, independentemente do tempo presente, passado ou futuro a elas associado.

Espinosa enfatiza ainda que essa flutuação do ânimo não ocorre apenas quando a dúvida está presente ou quando associamos um afeto a uma coisa acidentalmente, mas "no mais das vezes", quando somos afetados pelo mesmo objeto. Assim, um mesmo objeto pode ser causa eficiente e não acidental de múltiplos e contrários afetos, ou seja, haverá uma transferência afetiva de amor ou ódio ao mesmo e único objeto. Devido à complexidade do corpo humano, ele pode afetar e ser afetado de variadas maneiras por um só e mesmo corpo ou objeto e vice-versa, além de que um objeto também poderá afetar de muitas e diversas maneiras uma só e a mesma parte do corpo, compondo o que Chauí (2016, p. 636, nota 35) denomina um "sistema das afecçôes corporais".

Qual é o prejuízo atribuído à flutuação do ânimo em relação à flutuação da imaginação, além de serem fonte de dúvidas cognitivas e oscilaçôes afetivas? Enquanto a flutuação da imaginação produz a ideia de contingência, independentemente do tempo a ela associado, através da ideia de possível, a flutuação do ânimo pode contribuir para a produção da flutuação da imaginação. Dessa forma, a flutuação da imaginação, isto é, a cognitiva ligada à contingência e ao possível, pode ser desencadeada pela flutuação do ânimo, ou seja, afetiva, já que é um estado em que o indivíduo está perturbado e precisa decidir sobre qual ação ou ideia ele deve tomar. ${ }^{9}$ Conforme acrescenta Chauí (2016, p. 335):

Da mesma maneira, também o ânimo flutua sob a ação de afetos contrários simultâneos e essa flutuação afetiva é mais intensa do que a cognitiva, pois poderá desencadear efeitos cognitivos, isto é, a contrariedade dos afetos atuará sobre a dúvida quanto aos acontecimentos.

Quando o menino percebe que a regularidade entre os passantes foi quebrada, a sua imaginação flutua a ponto de conceber o passado, o presente ou o futuro como contingentes.

contingentemente como futuros. E esta flutuação da imaginação será a mesma se for a imaginação das coisas que contemplamos da mesma maneira com relaçáo ao tempo passado ou ao presente, e consequentemente imaginaremos como contingentes as coisas relacionadas tanto ao tempo presente quanto ao passado ou o futuro." (ESPINOSA, 2015, EII P44 esc., p. 207-209).

9 "Por afetos contrários entenderei na sequência, os que arrastam os homens em sentidos diversos, ainda que sejam do mesmo gênero, como a gula e a avareza, que são espécies de amor; e eles não são contrários por natureza, mas por acidente." (ESPINOSA, 2015, EIV def. 5, p. 379-381). 
No entanto, o passado e o futuro são apenas dimensóes internas do presente, ${ }^{10}$ por isso, quanto mais flutuaçóes do ânimo existirem no tempo presente, maior será a necessidade de retornar ao passado ou imaginar o futuro. Em outras palavras, a contingência e a contrariedade dos afetos no presente incitam o conatus a reviver ou a projetar afetos vividos e concatenados em sua memória: "O homem, a partir da imagem de uma coisa passada ou futura, é afetado pelo mesmo afeto de Alegria ou Tristeza que a partir da imagem de uma coisa presente." (ESPINOSA, 2015, EIII P18, p. 267).

Impossibilitado de contemplar com alegria a presença de Jacó, pois a sua imagem excluiu a presença da imagem de Simeão que o tornava alegre, o menino irá aguardar a possibilidade de revê-lo contingentemente no futuro. Caso não seja possível em breve, ele vai reviver os momentos nos quais houve a oportunidade de encontrá-lo, já que a variação afetiva é a mesma, independentemente do tempo a ela relacionado. Conforme observa Matheron (1988, p. 127), “[...] uma imagem é sempre uma imagem e, enquanto nós nos limitamos a considerá-la nela mesma, o sentimento que lhe é ligado permanece invariável." Espinosa afirma que, durante o tempo em que o homem é afetado pela imagem de alguma coisa, ele contemplará a coisa como presente, embora ela não exista (ESPINOSA, 2015, EII P17, p. 165). Essa imaginação das coisas não existentes é aquela associada em sua memória, que pode ser tanto passada quanto futura, dependendo da imagem do tempo a ela associada. A diferença dos tempos, quando é apenas imaginada, leva a mente ao sentimento da contingência das coisas e à incerteza sobre o desenrolar dos fatos.

\section{A ILUSÃo dA CONTINGÊNCIA AFETIVA}

Alquié enfatiza a força que a imaginação exerce sobre nosso conhecimento da realidade, pois ela é aquilo que nos é mais essencial, o nosso

\footnotetext{
${ }^{10}$ A ilusão da contingência produzida pelo conhecimento imaginativo entre os modos finitos ocorre, porque não conseguimos perceber a ideia de uma sucessão necessária, isto é, da ordem necessária da natureza que sustenta a duração ou existência das coisas particulares. Assim, a ligação entre passado, presente e futuro é descontínua, não conseguimos perceber as causas que produzem ou excluem um determinado modo na existência. Espinosa define a contingência pelo desconhecimento das causas de produção de determinadas coisas singulares, isto é, pela ausência ou dúvida em relação à determinação: "Chamo contingentes as coisas singulares, enquanto, ao prestarmos atenção à só essência delas, nada encontramos que ponha necessariamente sua existência ou que necessariamente a exclua." (ESPINOSA, 2015, EIV def. 3, p. 379). Conforme observa Israël, a contingência se inscreve numa certa forma temporal, que não é nada além da duração imaginada: "O tempo e a contingência são duas abstraçôes que derivam do mesmo processo imaginativo, o qual oculta a maneira pela qual os modos dependem da substância." (2001, p. 94).
} 
instinto básico de conservação: "Vemos que, para Espinosa como para todos os cartesianos, a imaginação e a percepção, consideradas nelas mesmas e tal como elas se oferecem a nossa consciência, são indiscerníveis." (ALQUIÉ, 1981, p. 200). Segundo Espinosa, a imaginação não é uma faculdade pela qual representamos um objeto ausente e que sabemos ausente. De fato, imaginando, tendemos a crer que a imagem é real, tal como acontece nos sonhos ou na alucinação. Quando imaginamos, a constituição do corpo pode se encontrar da mesma maneira, quer na presença, quer na ausência do objeto. As sensaçóes e imagens formadas pelo encontro com os corpos ou suscitadas pela memória são puramente subjetivas e exprimem o estado momentâneo em que o corpo se encontra.

Valendo-se do exemplo de Espinosa, quando Paulo percebe Pedro, a ideia que Paulo tem de Pedro não representa somente Pedro, mas o estado atual do corpo de Paulo. Ao perceber Pedro, Paulo tem a impressão que esse objeto é Pedro, mas essa percepção é gerada pelo corpo de Paulo, afetado pela presença de Pedro. Tal como acrescenta Alquié: "Assim, para Espinosa como para todos os cartesianos, nós estamos no conhecimento sensível fechados em nós mesmos." (1981, p. 201, n. 1). Isto é, quando estamos em estado de passividade, não existe um "fora de nós"11, estamos determinados externamente e somos causa apenas parcial daquilo que percebemos. De fato, pensar uma coisa como passada é imaginar a forma como fomos afetados, enquanto pensála como futura é imaginar que essa ocorrência poderá novamente se repetir. Assim, podemos ver novamente aquilo que vimos ou ver aquilo que poderemos rever; podemos nos revigorar com aquilo que nos revigorou ou revigorará; podemos nos lesar com aquilo que nos lesou ou lesará etc. (ESPINOSA, 2015,

\footnotetext{
${ }^{11}$ Como observa Jaquet, o modo é um lugar de trocas entre interior e exterior, já que ele é perpetuamente afetado. Uma afecção sempre envolve a natureza de nosso corpo e aquela do corpo exterior: "Ela é uma mistura frequentemente confusa de interioridade e exterioridade, de modo que é difícil desembaraçar o que pertence a si e aos outros." (2017, p. 59). O que primeiramente Espinosa nos mostra é que aquilo que cremos ser interior, na verdade, é exterior. Dito de outro modo, o que nos aparece como uma determinaçáo interior é uma determinaçáo exterior que ignoramos: "Espinosa frustra a ilusão de um sujeito pessoal, de um si imaginário que não é senão alteridade oculta." (2017, p. 60). Nesse sentido, todas as ideias, julgamentos, esforços e açóes que pensamos nos pertencer e que constituem nossos hábitos, lembranças e paixōes são fruto de uma intervenção de causas exteriores, pela maneira como somos afetados e as imaginamos. Podemos perceber que, na passividade, não existe um fora de nós, justamente porque a exterioridade não se define por aquilo que está fora de nós, mas sim de uma interiorização da exterioridade: "A exterioridade não se define, entẫo, necessariamente pelo que está fora de nós, ela está em nós sob a forma da presença dos traços dos corpos que nos afetam." (2017, p. 61). Espinosa irá nos conduzir ao conhecimento dos afetos, para percebermos como é construída essa imagem de nós mesmos e como nos tornamos dependentes das causas exteriores, para a conservação de nossa potência de agir.
} 
EIII P18 esc., p. 267). Para Espinosa, enquanto imaginamos, afirmamos a existência da coisa, presente ou ausente, desde que o corpo não seja afetado por nenhum afeto que suprima a existência dela.

A memória nasce quando os vestígios são ligados por uma continuidade material e associados pela concomitância produzida no corpo. Observa Drieux (2014, p. 150): "A concatenação, tomada em seu sentido literal, induz efeitos mentais.” Toda e qualquer afecção corporal, entendida como paixão, corresponde na mente a uma afirmação da presença do corpo exterior que consideramos como sua causa. Entretanto, como complementa Drieux, a afecção no presente é solidária de um contexto, pois a afirmação da presença sempre se refere a um contexto determinado. Todo horizonte de espera produzido pela memória se condensa na própria percepçáo do presente. A memória está mais ligada à produção da imagem do que propriamente à produção da lembrança, porque a memória é inicialmente uma certa regra na produção espontânea das imagens. É justamente essa regra de encadeamentos de imagens que acompanha e determina a percepção das coisas: "O que eu vejo se destaca - ou justamente não se destaca - sobre o fundo do que eu espero a ver, e esse horizonte depende da história de minhas disposiçóes corporais." (DRIEUX, 2014, p. 150).

Para Espinosa, a percepção náo pode ser concebida apenas como recepção das impressóes, tal como uma tábula rasa, mas há uma dimensão ativa e interna na produção dos vestígios que concerne a uma multiplicidade de causas que concorrem para a produção da afecção: "Essa causalidade interna ligada à retenção contém também uma dimensão ativa que sugere de instante em instante o que deve ser percebido.” (DRIEUX, 2014, p. 151). Assim, a distinção entre lembrança e percepção atual - passado, futuro ou presente - acontece no sujeito perceptivo e surge a partir do conflito de imagens concorrentes. Quando não há conflito do ânimo ou cognitivo, a percepção permanece no tempo presente, no horizonte de espera, em seu conjunto, isto é, como percepção atual. Portanto, a memória não se relaciona exclusivamente a uma lembrança, mas inicialmente funciona como uma determinação da percepção atual e, mais frequentemente, surge no campo perceptivo, quando o horizonte da espera da percepção atual é desapontado. A frustração diante do momento presente ocasionada pela diminuição de potência (tristeza) induz o indivíduo a buscar nas memórias passadas momentos ou soluçôes para fugir ou superar o momento de desapontamento. 
Desde a P18 da Parte II, Espinosa afirma que a mente percebe, em função de um padrão, e antecipa a repetição dos mesmos acontecimentos que comporão a percepção do tempo, da contingência e do possível:

Apoiando-se sobre os encadeamentos da memória, a mente adquire uma capacidade de imaginar informada, em sentido próprio: projetando um horizonte de espera, os encadeamentos da memória fazem surgir a possibilidade da diferença entre o possível e o real, abrem a dimensão da contingência. (DRIEUX, 2014, p. 154).

Os encadeamentos nos fazem sair da afirmação unilateral da presença do que nos afeta. Nessa perspectiva, as possibilidades de flutuação que são abertas conduzem à estruturação, particularmente temporal, da experiência. Entretanto, a afirmação da presença das afecções presentes, passadas ou futuras é uma necessidade que está ligada à natureza da imagem (afecção) e não a uma simples possibilidade de escolha entre afecçôes contrárias. A ilusão da escolha produz a ideia de liberdade indeterminada como poder dos contrários, independentemente do tempo associado.

Eis o grande problema de pensar as categorias de contingência e possível: elas são responsáveis pela produção da flutuação da imaginação e do ânimo e viceversa. Quando o conatus entra nessa dinâmica, seja ele mais imaginativo, seja mais afetivo, o indivíduo permanece em dúvida em relação aos acontecimentos, principalmente relacionados com o tempo passado ou futuro. Tanto o amor quanto o ódio, pelo fato de estarem associados ao tempo, possuem um caráter ao mesmo tempo retrospectivo ou prospectivo, pois eles são compreendidos com respeito a uma lembrança ou ao desejo de imaginá-los no futuro. Nada impede que esses dois afetos possam ser imaginados sem qualquer nuance afetiva, apenas como experiência vivida ou possibilidade de sua realização. Todavia, o tempo futuro é uma projeção do passado, construída através da ligação das concatenaçôes na memória corporal; assim ele é necessariamente incerto, já que não podemos ter um conhecimento adequado da duração das coisas.

Quanto ao tempo passado, devido à multiplicidade de afecçóes pelas quais somos constantemente afetados, não podemos senão reter uma pequena parte ou traços na memória. Essa constituição flutuante do corpo e da mente em relaçáo às afecçôes de alegria e tristeza inconstantes gera novos afetos, tais como a esperança (spes) e o medo (metus), os quais determinam a ação do conatus a duvidar dos acontecimentos quanto às coisas exteriores: "Pois a Esperança é nada outro que a Alegria inconstante originada da imagem de uma coisa futura 
ou passada, de cuja ocorrência duvidamos. O Medo, ao contrário, é a Tristeza inconstante originada da imagem de uma coisa duvidosa." (ESPINOSA, 2015, EIII P18 esc. 2, p. 269). Encarcerada pelas lembranças do passado ou pelas possibilidades do futuro, a mente está suspensa pela dúvida, não pela suspensão de julgamento de um ou outro afeto, mas pela concorrência de ideias contrárias.

Por esse motivo, Espinosa irá afirmar que não pode haver esperança sem medo, nem medo sem esperança. ${ }^{12}$ Quando imaginamos os futuros contingentes, isto é, os possíveis, em relação à coisa que amamos, ao mesmo tempo que imaginamos a sua possibilidade, nos alegramos, porém, necessariamente também imaginamos a sua impossibilidade e nos entristecemos. No entanto, esses obstáculos que excluem a presença da coisa amada são também duvidosos e, dependendo da variação afetiva da ideia da coisa amada, a mente excluirá as ideias dos obstáculos que a impedem de pensar na possibilidade de possuir ou conservar a ideia da coisa amada: "O ato de duvidar, de perceber simultaneamente duas ideias contrárias, é o que separa as coisas passadas ou futuras de sua ocorrência, relegando-as assim à categoria de simples possíveis." (ISRAËL, 2001, p. 143). Nessa linha, a dúvida quanto à ocorrência de algo que nos parece bom produz a flutuação do ânimo, porque a esperança de sua possibilidade entra em conflito com o medo de sua impossibilidade. A mente entra num estado de modificação entre dois afetos contrários, isto é, numa "oscilação dinâmica" (ISRAËL, 2001, p. 148), onde momentos de segurança se alternam com momentos de desespero.

A contingência em relação aos acontecimentos passados ou futuros produz a ideia de possível, aqui entendido como paixão da mente submetida aos encontros acidentais na ordem comum da natureza. A dúvida, quer sobre o passado, quer sobre o futuro, produz os afetos de esperança ou medo, que nada mais são do que a ideia de possível em relação ao tempo passado ou futuro. Assim, quando esperamos, isto é, pensamos ser possível possuir ou conservar a coisa amada ou excluir a coisa odiada, nós tememos, pela própria definição da esperança, “[...] o que se opóe à realização do nosso desejo." (MATHERON, 1988, p. 127). De fato, se o conatus se esforça em imaginar o que traz alegria e não em imaginar o que entristece, então ele sempre tentará

\footnotetext{
${ }^{12}$ Conforme a explicação da Definição dos Afetos: "Com efeito, supóe-se que quem está suspenso pela Esperança e duvida da ocorrência da coisa imagina algo que exclui a existência da coisa futura; por isso se entristece e, consequentemente, enquanto está suspenso pela Esperança tem medo que a coisa não ocorra. Quem, pelo contrário, está com Medo, isto é, duvida da ocorrência da coisa que odeia, também imagina algo que exclui a existência da coisa; por isso se alegra e, consequentemente, tem Esperança de que não ocorra." (ESPINOSA, 2015, EIII Def. dos afetos 13 expl., p. 347).
} 
afastar o medo, para permanecer esperançoso dos desenlaces da fortuna, a qual muda sem cessar e de maneira quase sempre imprevisível. A fortuna, que possui uma dupla face - ora favorável, ora desfavorável - somente existe para aquele que está em conflito de ânimo, suspenso entre a esperança e o medo.

Conforme observa Marilena Chauí (2016, p. 339), medo e esperança somente serão suprimidos, quando a dúvida acerca dos acontecimentos for suprimida: "[...] ainda que permaneça insuperável o sentimento de contingência - a incerteza quanto ao curso das coisas singulares." Nesse sentido, suprimida a dúvida desses afetos, outros afetos serão produzidos a partir da imagem alegre ou triste de uma coisa que temíamos ou esperávamos: quando nosso esforço tem êxito, da esperança liberada do medo produz-se a segurança (securitas), porém, quando o esforço fracassa, do medo liberto da esperança produz-se o desespero (desperatio). Chauí (2016, p. 339) acrescenta que, apesar de a tendência em imaginar seja a de priorizar as coisas no presente, "[...] esse presente em si mesmo é um vazio (o evento será ou já foi) preenchido pelos afetos, que presentificam o que ainda não é ou o que já não é." Entretanto, a ausência de dúvida nesses afetos derivados não significa presença da certeza: "[...] simplesmente a imaginação traz o passado e o futuro para o presente, excluindo imagens de tudo quanto possa impedir essa presença, mas sem qualquer garantia de que o contrário não teria sido possível, uma vez que tudo é experimentado como contingente." (CHAUÍ, 2016, p. 340).

Chauí enfatiza ainda que essa presentificação, que não elimina a contingência, é mais evidente, quando sentimos o alívio ou a aflição que a imagem da flutuação do ânimo causou, quando a retomamos, isto é, a presentificamos pelos afetos de gozo (gaudium) ou de remorso (conscientia morsus): "O Gozo, ademais, é a Alegria originada da imagem de uma coisa passada, de cuja ocorrência duvidáramos. O remorso, enfim é a tristeza oposta ao gozo.” (ESPINOSA, EIII P18 esc. 2, p. 269). É importante notar que o gozo ou júbilo pode aumentar subitamente as nossas esperanças, enquanto o remorso pode diminuí-las, aumentando o medo em relaçáo ao desenrolar dos fatos, na ordem comum da natureza.

Qual é o problema de o menino imaginar como um futuro contingente, isto é, como possível, ocorrer novamente a ordem dos passantes? O problema é que o menino não sabe que está imaginando, então, ele acredita que as coisas são contingentes por natureza: instala-se a flutuação do ânimo. No entanto, a imaginação em si mesma não é fonte de erros, mas erramos, quando não possuímos a ideia que exclui a presença das coisas que imaginamos. $\mathrm{O}$ problema 
é negligenciarmos o presente, porque estamos enclausurados no passado ou presos dentro de nós, projetando um futuro possível que reproduzirá cadeias de afecçóes passadas. A alegria passada ou futura torna-se a válvula de escape para o conatus fugir das tristezas ou conflitos do ânimo que estão presentes. Conforme salienta Alquié (1981, p. 311), negligenciamos a nossa experiência direta: "Já que, estritamente falando, não temos jamais a experiência direta senão de nosso presente e podemos considerar que passado e futuro são somente, para nós, imaginados." Ainda que o presente também seja apenas imaginado, é ele que nos proporciona uma multiplicidade de novas experiências alegres e a possibilidade de conservar aquilo que é mais útil ao homem: a potência do corpo em afetar e ser afetado. ${ }^{13}$

Entretanto, a derivação de afetos desencadeada pela identificação do objeto amado acompanha e completa a derivação por transferência afetiva (MATHERON, 1988, p. 143). A origem da identificação é bastante simples: "Quem imagina aquilo que ama ser destruído se entristecerá; porém se alegrará se o imagina ser conservado.” (ESPINOSA, 2015, EIII P19, p. 269). Há uma identificação do conatus com a coisa que é causa de amor, pois ele se torna o esforço de imaginar o mais vivamente possível a coisa amada, já que toda imagem que póe a existência dela o favorece pela alegria que ela causa. O conatus, isto é, o desejo torna-se dependente da alegria proporcionada pela imagem da coisa amada presente ou ausente: $o$ seu aumento de potência, isto é, a sua alegria depende apenas das causas exteriores.

Logo, quando o objeto amado está sob ameaça, mobilizaremos os recursos para defendê-lo e, caso ele escape de todas as ameaças, nós nos alegraremos por isso, como se nós mesmos estivéssemos em perigo. Há uma identificação entre o conatus do amante e da coisa amada, e Espinosa é muito preciso em definir o amor como a alegria conjuntamente à “ideia” da causa externa. ${ }^{14} \mathrm{~A}$ mera imagem da coisa amada é suficiente para que o afeto de

\footnotetext{
${ }^{13}$ Espinosa ressalta (2015, EIV P38, p. 439): “É útil ao homem o que dispóe o Corpo humano tal que possa ser afetado de múltiplas maneiras ou o que o torna apto a afetar os Corpos externos de múltiplas maneiras; e tanto mais útil quanto torna o Corpo mais apto a ser afetado e afetar os outros corpos de múltiplas maneiras; e, inversamente, é nocivo o que torna o Corpo menos apto a isto."

${ }^{14}$ Espinosa afirma que a vontade do amante em unir-se à coisa amada não exprime a essência do amor, mas apenas uma propriedade: "Mas cumpre notar que, quando digo ser uma propriedade no amante unir-se pela vontade à coisa amada, não entendo por vontade o consentimento ou a deliberaçáo do ânimo, ou seja, o decreto livre, nem tampouco o Desejo de unir-se à coisa amada, quando ela está ausente, ou de perseverar na presença dela, quando está lá; pois o amor pode ser concebido sem este ou aquele Desejo; por vontade, todavia, entendo o Contentamento que se dá no amante diante da presença da coisa amada e que corrobora, ou pelo menos fomenta, a Alegria do amante." (ESPINOSA, 2015, EIII, Definição dos afetos 6 expl., p. 343-345).
} 
alegria se manifeste em amor, uma vez que o amor ou contentamento pela imagem da coisa é anterior ao desejo, isto é, ao apetite de unir-se à coisa.

Porém, há também a contra-identificação do conatus ao objeto odiado: "Quem imagina aquilo que odeia ser destruído se alegrará." (ESPINOSA, 2015, EIII P20, p. 271). Tanto a identificação quanto a contra-identificação dos objetos amados ou odiados são complexificadas, quando esses objetos também possuem sentimentos. Assim, imaginar o objeto amado alegre é imaginar que a sua conservação está mais assegurada que antes, e imaginá-lo triste é imaginar que a sua perda pode estar próxima. Segundo Espinosa, as variaçóes afetivas dessas identificações são proporcionais às variações afetivas que experimenta a coisa amada (ESPINOSA, 2015, EII, P21, p. 271). Por sua vez, essas variações afetivas são também transferidas para os objetos que imaginamos causar alegria ou tristeza no objeto amado (ESPINOSA, 2015, EIII P22, p. 273). Por outro lado, na contra-identificação surge a inveja (Invidia): nós nos alegramos com a tristeza do ser odiado e nos entristecemos com a sua alegria, odiamos o que o alegra e amamos o que o entristece (ESPINOSA, 2015, EIII P23 e 24, p. 273-275). É importante observar que todos esses afetos são derivados, porque tentamos imaginar os afetos que os outros seres possuem em relação a nós ou à coisa amada ou odiada submetidos ao acaso dos encontros na ordem comum da natureza.

\section{A ILUSÁo dA IDEIA DE FINALIDAdE}

A ilusão da contingência originada pela ideia de possíveis contrários encobre a ação necessária do conatus, na produção imaginativa. A identificação do conatus com o objeto amado conjuntamente com a ideia de contingência produzirão todos os meios possíveis para conservar o objeto amado e afastar aquele odiado: "Esforçamo-nos para afirmar de nós e da coisa amada tudo que a nós ou a ela imaginamos afetar de Alegria; e, ao contrário, negar tudo que a nós ou a ela imaginamos afetar de Tristeza." (ESPINOSA, 2015, EIII P25, p. 277). A imaginação produz um universo de possíveis pelos quais, ilusoriamente, acreditamos nos conservar conjuntamente com a coisa amada. No entanto, pela própria inadequação da duração das coisas sob a ordem comum da natureza, também imaginamos os possíveis que excluem a possibilidade daquilo que odiamos em participar desse mundo imaginário: "Esforçamo-nos para afirmar da coisa que odiamos tudo que imaginamos 
afetá-la de Tristeza e, ao contrário, negar o que imaginamos afetá-la de Alegria.” (ESPINOSA, 2015, EIII P26, p. 277).

Fechado em si mesmo e alienado pela construção de seu imaginário, facilmente o homem estima além da medida a si eà coisa amada e, inversamente, aquém da medida à que odeia. Essa imaginação, quando diz respeito ao próprio homem que se estima além da medida, é Soberba (Superbia), e o filósofo a classifica como uma espécie de delírio: "[...] porque o homem sonha de olhos abertos poder todas as coisas que alcança pela só imaginação e que por isso contempla como se reais, e com elas exulta durante o tempo em que náo pode imaginar outras que excluem a existência destas e limitam sua própria potência de agir." (ESPINOSA, 2015, EIII P26 esc., p. 277). A potência de agir do homem é limitada, porque a flutuação da imaginação e do ânimo entre aquilo que é possível e aquilo que limita a sua possibilidade conduz o homem à inação, isto é, a permanecer na passividade e a acreditar que constrói o seu mundo imaginário livremente. As causas eficientes da produção das ideias de possíveis são imaginadas como causas finais. O homem planeja um destino, e todos os meios para atingi-lo tornam-se a finalidade de suas açóes.

Entretanto, todos os obstáculos e contratempos que surgem entre uma finalidade e outra levam o homem a experimentar a fraqueza da vontade em relação aos objetivos estabelecidos. Fechado em si mesmo, perseguindo os objetos amados e experimentando a impossibilidade de fruí-los, o homem experimenta as paixóes, e a contingência surge como um drama pelo qual ele busca a felicidade: "Donde revela-se sermos agitados por causas externas de muitas maneiras e flutuarmos, tal qual ondas do mar agitadas por ventos contrários, ignorantes dos desenlaces e do destino." (ESPINOSA, 2015, EIII P59 esc., p. 337). Conforme acrescenta Chauí (2016, p. 336), a advertência de Espinosa em relação à flutuação do ânimo é decisiva, porque "[...] é a marca mais profunda da inconstância e fragilidade das paixóes", pois ela ocorre no desejo passivo e será a chave para compreendermos a servidão humana. A flutuaçâa do ânimo é sintetizada pelo filósofo, no verso trágico do poeta Ovídio: "Vejo o melhor e o aprovo, sigo o pior." A ilusão da liberdade de escolha, na verdade, nada mais é do que a experiência da futuação do ânimo.

\section{Consideraçốes FinaIs}

Desse modo, percebemos que o desconhecimento da lógica do conatus, que envolve a produção das paixóes, é responsável pela ilusão da escolha 
livre ou indeterminada. Tanto a flutuação do ânimo quanto da imaginação, originadas da constituição da mente afetada por afetos contrários, produz a ilusão da contingência, através das ideias de possíveis contrários. Apenas a compreensão adequada dos desejos, isto é, dos apetites (afetos), enquanto nos determinam à ação, pode nos auxiliar a compreender a ordem necessária da natureza e eliminar, ou ao menos moderar, os conflitos do ânimo e da imaginação produzidos pela ordem comum da natureza e que surgem através dos objetos amados e que são perseguidos como se fossem fins.

Por conseguinte, apenas a compreensão adequada do conatus nos faz perceber a sua lógica, a qual envolve a identificação das causas eficientes das nossas paixôes e açóes, e, apesar de surgirem através do signo da utilidade e finalidade, são expressões da determinação da causalidade eficiente imanente à qual todos os modos singulares estâo submetidos, por meio da ordem necessária da natureza.

RODRIGUES, J. L. The imaginative Conatus in Spinoza: the production of contingency and the idea of purpose. Trans/form/ação, Marília, v. 44, n. 1, p. 205-224, Jan./Mar., 2021.

\begin{abstract}
The scope of this article is to explain the logic of the production of passions through the imaginative conatus in Spinoza. This logic involves the understanding of the primitive affections of joy, sadness and desire that will compose the passions for which we are determined to think and act, and at the same time, produce the illusion of freedom of undetermined choice. We will see how this logic of the imaginative conatus, when suffering the vacillation of mind, will produce the contingent and possible modalities that are responsible for the illusion of indeterminate choice, that is, of free will. We will try to demonstrate that the experience of freedom as the power of opposites for which men believe to determine the ends for which the appetite/desire changes in passions is reduced to the experience of the vacillation of mind. This illusion of undetermined freedom arises because men do not adequately know their essence (conatus), a fact that leads them to identify the efficient causes of the production of affections as final causes.
\end{abstract}

Keywords: Freedom. Passions. Affections. Possible. Contingent. Spinoza. 


\section{REFERÊNCIAS}

ALQUIÉ, F. Le rationalisme de Spinoza. Paris: PUF, 1981.

ESPINOSA, B. Ética. Tradução do Grupo de Estudos Espinosanos; coordenação de Marilena Chauí. São Paulo: Editora da Universidade de São Paulo, 2015.

CHAUÍ, M. A Nervura do real II: imanência e liberdade em Espinosa. São Paulo: Companhia das Letras, 2016.

DRIEUX, P. Perception et sociabilité: La communication des passions chez Descartes et Spinoza. Paris: Classiques Garnier, 2014.

ISRAËL, N. Spinoza. Le temp de la vigilance. Paris: Payot, 2001.

JAQUET, C. Spinoza à l'œuvre: composition des corps et force des idées. Paris: Publications de la Sorbonne, 2017.

MACHEREY, P. Introduction à l'Éthique de Spinoza. 5 v. Paris: PUF, 1994-1998.

MATHERON, A. Individu e communauté chez Spinoza. Paris: Les Éditions de Minuit, 1988.

RODRIGUES, J. L. Identidade entre ideia e volição na Ética de Espinosa. Cadernos Espinosanos, São Paulo, v. 1, n. 31, p. 89-116, 2014.

Recebido: 16/6/2020

Aceito: 15/7/2020 